\title{
Advanced Sulfur Control Concepts for Hot Gas Desulfurization Technology
}

\author{
Quarterly Report \\ January 1 - March 31, 1998
}

Work Performed Under Contract No.: DE-AC21-94MC31258

\author{
For \\ U.S. Department of Energy \\ Office of Fossil Energy \\ Federal Energy Technology Center \\ P.O. Box 880 \\ Morgantown, West Virginia 26507-0880 \\ By \\ Research Triangle Institute \\ P.O. Box 12194 \\ Research Triangle Park, North Carolina 27709
}




\section{Disclaimer}

This report was prepared as an account of work sponsored by an agency of the United States Government. Neither the United States Government nor any agency thereof, nor any of their employees, makes any warranty, express or implied, or assumes any legal liability or responsibility for the accuracy, completeness, or usefulness of any information, apparatus, product, or process disclosed, or represents that its use would not infringe privately owned rights. Reference herein to any specific commercial product, process, or service by trade

name, trademark, manufacturer, or otherwise does not necessarily constitute or imply its endorsement, recommendation, or favoring by the United States Government or any agency thereof. The views and opinions of authors expressed herein do not necessarily state or reflect those of the United States Government or any agency thereof. 


\section{TABLE OF CONTENTS}

Section

Page

1.0 CONTRACT OBJECTIVE $\ldots \ldots \ldots \ldots \ldots \ldots \ldots \ldots \ldots \ldots \ldots \ldots \ldots$

2.0 TECHNICAL APPROACH $\ldots \ldots \ldots \ldots \ldots \ldots \ldots \ldots \ldots \ldots \ldots \ldots \ldots$

3.0 CONTRACT TASKS $\ldots \ldots \ldots \ldots \ldots \ldots \ldots \ldots \ldots \ldots \ldots \ldots \ldots \ldots$

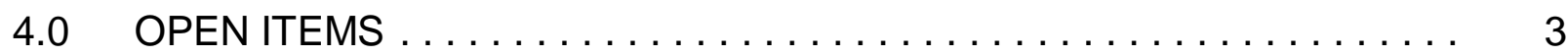

5.0 PLANS FOR NEXT QUARTER $\ldots \ldots \ldots \ldots \ldots \ldots \ldots \ldots \ldots \ldots \ldots \ldots$

\section{LIST OF FIGURES}

Figure

Page

1 Process flow diagram for AHGP Mobile Laboratory $\ldots \ldots \ldots \ldots \ldots$

2 PFD and material balance for RTI equipment at PSDF .......... 6

3 Proposed arrangement of Mobile Laboratory and DSRP skid for PSDF field test

4 Revised proposed arrangement of Mobile Laboratory and DSRP skid

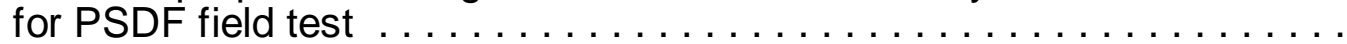




\section{CONTRACT OBJECTIVE:}

The objective of this project is to develop a hot-gas desulfurization process scheme for control of $\mathrm{H}_{2} \mathrm{~S}$ in HTHP coal gas that can be more simply and economically integrated with known regenerable sorbents in DOE/METC-sponsored work than current leading hot-gas desulfurization technologies. In addition to being more economical, the process scheme to be developed must yield an elemental sulfur byproduct.

\section{TECHNICAL APPROACH:}

The Direct Sulfur Recovery Process (DSRP), a leading process for producing an elemental sulfur byproduct in hot-gas desulfurization systems, incurs a coal gas use penalty, because coal gas is required to reduce the $\mathrm{SO}_{2}$ in regeneration off-gas to elemental sulfur. Alternative regeneration schemes, which avoid coal gas use and produce elemental sulfur, will be evaluated. These include (i) regeneration of sulfided sorbent using $\mathrm{SO}_{2}$; (ii) partial oxidation of sulfided sorbent in an $\mathrm{O}_{2}$ starved environment; and (iii) regeneration of sulfided sorbent using steam to produce $\mathrm{H}_{2} \mathrm{~S}$ followed by direct oxidation of $\mathrm{H}_{2} \mathrm{~S}$ to elemental sulfur. Known regenerable sorbents will be modified to improve the feasibility of the above alternative regeneration approaches. Performance characteristics of the modified sorbents and processes will be obtained through lab- and bench-scale testing. Technical and economic evaluation of the most promising processes concept(s) will be carried out.

\section{CONTRACT TASKS:}

\section{Phase I - Concept Assessment:}

Completed.

\section{Phase II:}

\section{Economic Analysis and Process Simulation}

The final report prepared by North Carolina State University (NCSU) that compares a conceptual Advanced Hot Gas desulfurization Process (AHGP) - using direct $\mathrm{SO}_{2}$ regeneration - with DSRP was received and reviewed. A copy was provided to DOE for comments. In addition to the hard copy of the report, NCSU furnished an electronic version and electronic versions of all the supporting calculations (spreadsheets, tables, and diagrams). Also, NCSU provided copies of the ASPEN PLUS input files that were used to generate the process simulations and economic calculations; these files would be the logical starting point for any future process simulation work. 
The review of the the draft NCSU report (Quaterly Technical Progress Report dated January 22,1998$)$ noted that in the process simulations the system pressure drops were probably understated, and resulted in low estimates for the $\mathrm{SO}_{2}$ recycle compressor horsepower (in the AHGP case) and low air compressor horsepower for the DSRP case. For the final report NCSU revised the simulations and increased compressor sizes and duties; the economic evaluation includes the revised figures.

The final conclusions reached in the NCSU study were not changed by the adustments made to the process simulations. The AHGP has higher capital costs than a DSRP-based hot gas desulfurization (HGD) process. Also, the AHGP appears to be a more complicated process to operate because the $\mathrm{SO}_{2}$ recirculation loop must be balanced by reactions that consume and produce $\mathrm{SO}_{2}$. However, the AHGP consumes less coal gas, and this gives it an operating cost advantage that outweighs the capital cost penalty, according to the NCSU analysis. The advantages with the AHGP increase significantly with increasing sulfur content of the coal and increasing plant size. Despite its higher installed cost, AHGP is seen to outperform financially the DSRP in under 2 years for 100 to $500 \mathrm{MWe}$ plants running on high sulfur coal.

An executive summary is being drafted that, combined with a copy of the report, will become a topical report.

\section{Bench-Scale Sorbent Testing}

No bench-scale test work was conducted this quarter. The sorbent is being modified to reduce loss of activity due to sintering. Four materials were prepared by varying calcination temperature ( 850 to $1000 \mathrm{EC}$ ) and additive concentration ( 5 to $10 \mathrm{wt} \%$ ). The resulting sorbents had surface areas ranging from 19 to $50 \mathrm{~m}^{2} / \mathrm{g}$. These sorbents are being prepared for pore volume analysis, followed by final preparation and microreactor testing.

\section{$\underline{\text { PSDF Field Test }}$}

The engineering and design efforts for the renovation to the Mobile Laboratory and its bench-scale sorbent test rig accelerated accelerated this quarter. Good communication channels were established with the key personnel at the PSDF following the December 19, 1997, meeting; detailed design information is being exchanged. A trip report and action item list was drafted, reviewed by all parties, and accepted. The process flow diagram (PFD) of the bench-scale AHGP unit was prepared and reviewed internally (Figure 1). In addition, a PFD with a detailed material balance (Figure 2) was prepared to show the feed and vent flows during the multiple operating modes that will be encountered with both the skid-mounted DSRP and the bench-scale AHGP units in operation. 
The specifics of the electrical hook up requirements have been determined and an additional power transformer will be required to connect the RTI equipment to the PSDF plant power. A proposal was prepared and sent to DOE contracts to cover the additional scope of work.

For the Mobile Laboratory renovation design, the layout of the laboratory/control room side of the trailer was the first priority. The interior plans are included in Figure 3, the proposed site plan and general equipment arrangement. In the process equipment side of the trailer, the rectangles designated AHGP1 and AHGP2 represent the equipment skids that were formerly the zinc titanate fluid bed desulfurization (ZTFBD) and Direct Sulfur Recovery Process (DSRP) units.

The site plan drawing (Figure 3) was mostly generated to satisfy the design needs of the field test of the skid-mounted DSRP field test unit, but it is still of interest to the AHGP project. The concept shown in this drawing is to have a single point connection for process and utility lines coming from PSDF and returning to PSDF, at one end of the DSRP skid. From that skid, branch lines will split off along the ladder rack shown, to feed the process equipment inside the trailer.

That initial site plan was rejected by the PSDF site contractor, Southern Company Services (SCS), because it required more length than the space available. A revised design was prepared (Figure 4) in which the DSRP skid was relocated from the end of the trailer to the side. This arrangement is less convenient for connecting the coal gas slipstream and plant utilities, but it shortens the "footprint" required for the RTI field test equipment. The revised site plan is currently being reviewed by SCS.

Five (5) sheets of Piping and Instrumentation Diagrams (P\&IDs) will be required to describe the AHGP process equipment, the analytical equipment interface, and the liquid $\mathrm{SO}_{2}$ delivery system. Four sheets have been drawn using the Rebis P\&ID software add-on to AutoCAD and are undergoing internal review.

\section{OPEN ITEMS}

The milestone date for submission of the topical report covering the economic analysis and process simulation was originally set for January 31, 1998. However,the revised final report was not received from N.C. State University until mid-February, 1998. A draft topical report is planned for submission by April 30, 1998.

\section{PLANS FOR NEXT QUARTER:}

! Complete the executive summary of the final report from NCSU and incorporate it into a topical report covering the economic analysis and process simulation. 
! Continue to conduct microreactor tests with selected sorbents.

! Continue the engineering design effort for refurbishing the Mobile Laboratory; start construction and fabrication activities.

JWP/2nd_QTR_98.wpd

$4 / 17 / 98$ 
Figure 1. Process flow diagram for AHGP Mobile Laboratory.

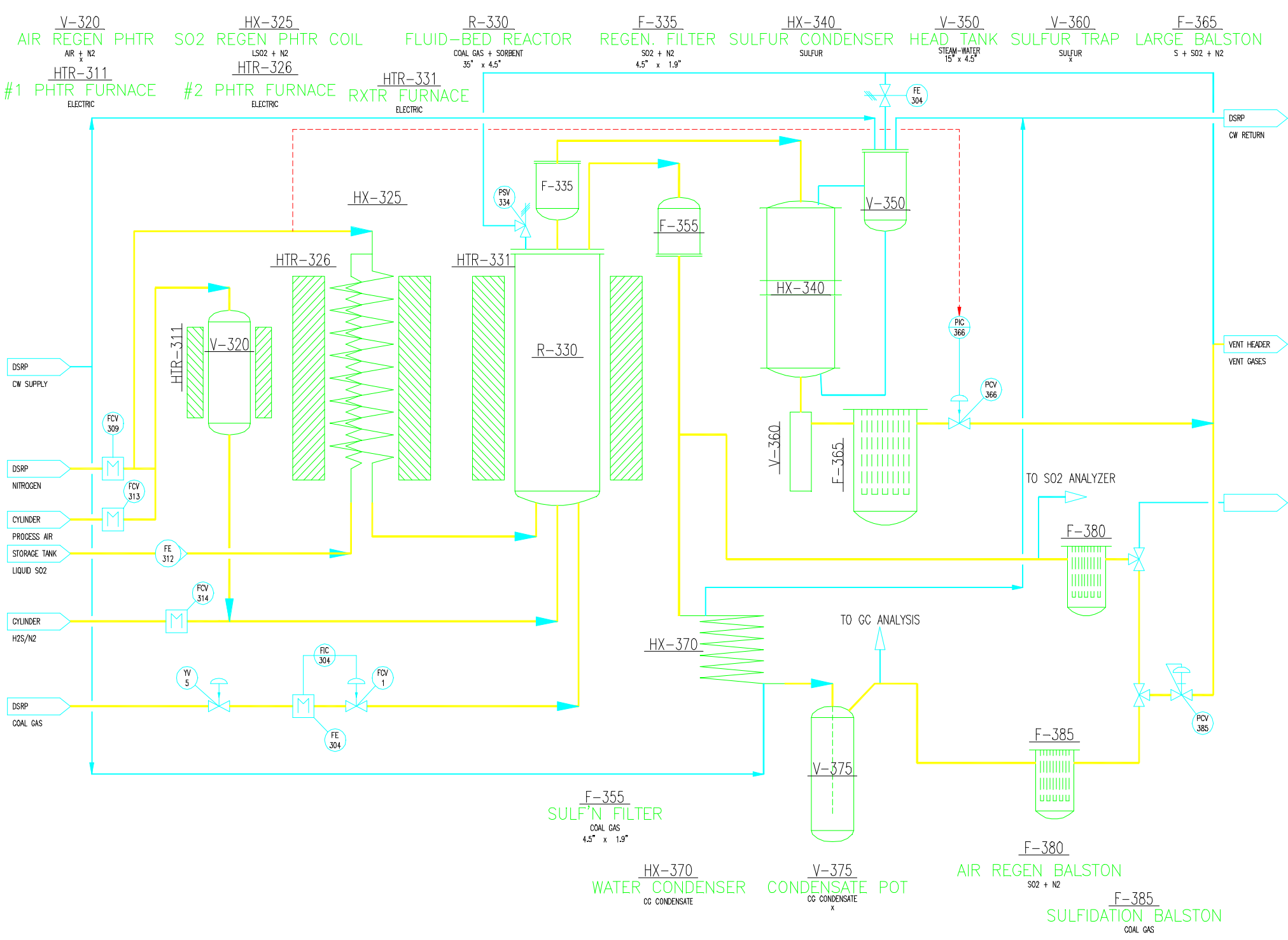


Figure 2. PFD and material balance for RTI equipment at PSDF.

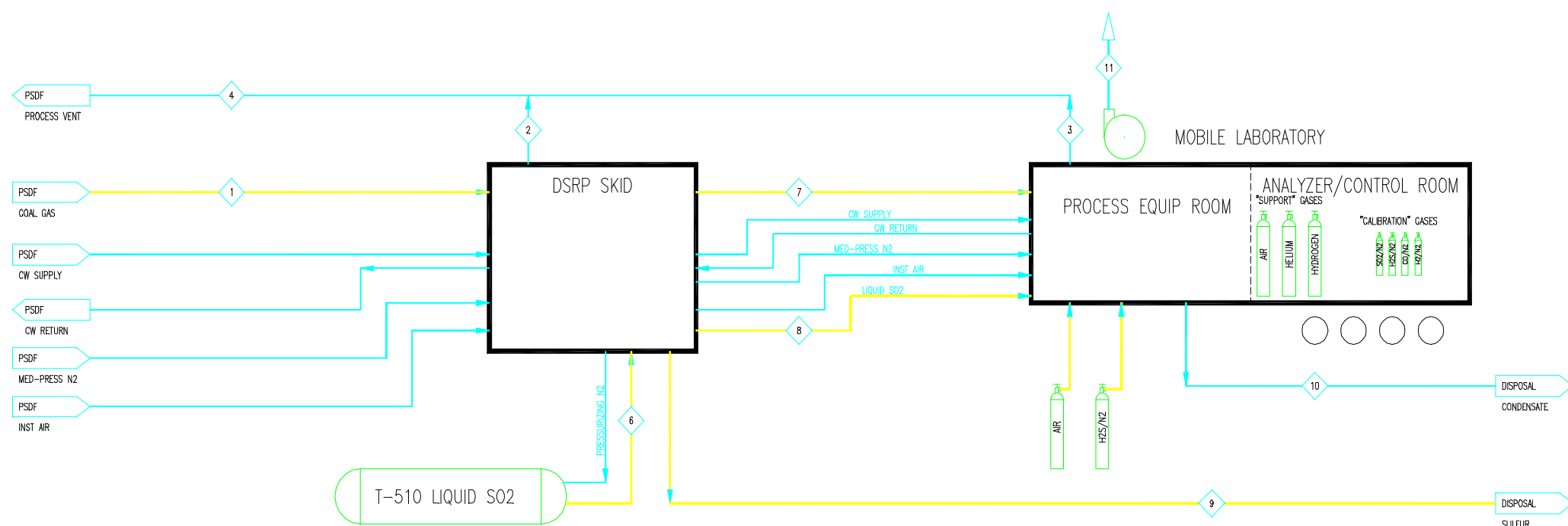

\begin{tabular}{|c|c|c|c|c|c|c|c|c|c|c|c|c|c|c|c|c|c|}
\hline STREAM N NMEER & 1 & 1 & 2 & 3 & 3 & 3 & 4 & 4 & 4 & 4 & 6 & 6 & 7 & 8 & 9 & 10 & 11 \\
\hline MOOE & $A, C, D$ & 8 & A & 8 & $c$ & $D$ & A & B & c & D & A & $c$ & B & c & $A, B, C, D$ & B & $\mathrm{A}, \mathrm{B}, \mathrm{C}, \mathrm{D}$ \\
\hline \multirow{2}{*}{\multicolumn{18}{|c|}{ 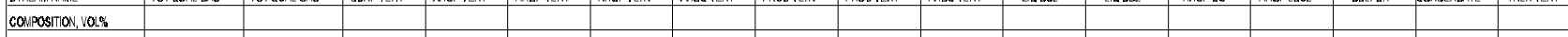 }} \\
\hline & & & & & & & & & & & & & & & & & \\
\hline$c_{0}$ & $185 \%$ & $18.5 \%$ & $00 \%$ & $19.6 \%$ & $0.0 \%$ & $0.0 \%$ & $0.0 \%$ & $5.4 \%$ & $0.0 \%$ & $0.0 \%$ & $0.0 \%$ & $0.0 \%$ & $185 \%$ & $0.0 \%$ & $0.0 \%$ & $0.0 \%$ & TRACE \\
\hline $\mathrm{CO}_{2}$ & $80 \%$ & $80 \%$ & $126 \%$ & $8.5 \%$ & $0.0 \%$ & $0.0 \%$ & $126 \%$ & $11.5 \%$ & $8.9 \%$ & $8.9 \%$ & $0.0 \%$ & $0.0 \%$ & $8.0 \%$ & $0.0 \%$ & $0.0 \%$ & $0.0 \%$ & TRACE \\
\hline $\mathrm{H}_{2} \mathrm{O}$ & $80 \%$ & $80 \%$ & $104 \%$ & $0.0 \%$ & $0.0 \%$ & $0.0 \%$ & $10.4 \%$ & $7.6 \%$ & $7.4 \%$ & $7.4 \%$ & $0.0 \%$ & $0.0 \%$ & $8.0 \%$ & $0.0 \%$ & $0.0 \%$ & $100.0 \%$ & TRACE \\
\hline $\mathrm{H}_{2}$ & $14.0 \%$ & 14.06 & $0.0 \%$ & $14.9 \%$ & $0.0 \%$ & $0.0 \%$ & $0.0 \%$ & $4.1 \%$ & $0.0 \%$ & $0.0 \%$ & $0.0 \%$ & $0.0 \%$ & 14.0\% & $0.0 \%$ & $0.0 \%$ & $0.0 \%$ & TRACE \\
\hline $\mathrm{H}_{2} \mathrm{~S}$ & $0.050 \%$ & $0.050 \%$ & $0.23 \%$ & $0.00 \%$ & $0.00 \%$ & $0.0 \%$ & $0.23 \%$ & $0.17 \%$ & $0.00 \%$ & $02 \%$ & $0.0 \%$ & $0.0 \%$ & $0.05 \%$ & $0.0 \%$ & $0.0 \%$ & $0.0 \%$ & TRACE \\
\hline $\mathrm{SO}_{2}$ & $0.0 \%$ & $00 \%$ & $0.11 \%$ & $0.00 \%$ & $50.0 \%$ & $0.67 \%$ & $0.19 \%$ & $0.08 \%$ & $14.67 \%$ & $0.28 \%$ & $100.0 \%$ & $100.0 \%$ & $0.0 \%$ & $100.0 \%$ & $0.0 \%$ & $0.0 \%$ & TRACE \\
\hline s & & & IRACE & & TRACE & $0.0 \%$ & TRACE & TRACE & TRACE & TRACE & & & & & $100.0 \%$ & & \\
\hline$\underline{O}_{2}$ & $0.0 \%$ & $00 \%$ & $00 \%$ & $00 \%$ & $0.0 \%$ & $00 \%$ & $0.0 \%$ & $0 . \%$ & $0.0 \%$ & $0.0 \%$ & $0.0 \%$ & $0.0 \%$ & $0.0 \%$ & $0.0 \%$ & $0.0 \%$ & $0.0 \%$ & $21.0 \%$ \\
\hline $\mathbb{N}_{2}$ & $51.5 \%$ & $51.5 \%$ & $76.6 \%$ & $57.0 \%$ & $50.0 \%$ & $99.3 \%$ & $766 \%$ & $712 \%$ & $689 \%$ & $832 \%$ & $0.0 \%$ & $0.0 \%$ & $51.5 \%$ & $0.0 \%$ & $0.0 \%$ & $0.0 \%$ & $79.0 \%$ \\
\hline FOW RATE, IBHR & 6 & 11 & 15 & 5 & 10 & 6 & 15 & 20 & 25 & 21 & 281 & 9.62 & 5.15 & 681 & 1.35 & 0.30 & \\
\hline FLW RATE, SCFH & 94 & 174 & 198 & 75 & 82 & 81 & 198 & 274 & 280 & 280 & & & 82 & & & & 400 SCFM \\
\hline FLOW RATE, GAUHR & & & & & & & & & & & 0.25 & 0.84 & & 0.60 & & 0.036 & \\
\hline TEMPERATURE, ${ }^{\circ} \mathrm{F}$ & 1000 & 1000 & 400 & 85 & 260 & 300 & 400 & 313 & 359 & 371 & 70 & 70 & 1000 & 70 & 70 & 85 & 70 \\
\hline \multirow{7}{*}{ 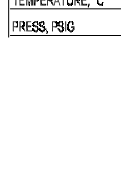 } & 538 & 588 & 204 & 29 & 127 & 149 & 204 & 156 & 182 & 188 & 21 & 21 & 538 & 21 & 21 & 29 & 21 \\
\hline & 279 & 279 & 15 & 15 & 15 & 15 & 15 & 15 & 15 & 15 & 350 & 350 & 279 & 350 & 0 & 0 & $2 \mathrm{wc}$ \\
\hline & SUFFXIETTER & EATING MODE & & & & & & & & & & & & & & & \\
\hline & A & DSPPS SKD ONNYY & & & ( & & & & & & & & & & & & \\
\hline & в & DSPP+ AHGP.SUL- & & & 50 CYCLES@ & & & & & & & & & & & & \\
\hline & c & DSPP+ AHGP.SO2 & ENERATION & & 50CYCLES@ & & & & & & & & & & & & \\
\hline & i & nCPP + AHFP.AR & ECFAREATIN & & 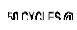 & & & & & & & & & & & & \\
\hline
\end{tabular}


Figure 3. Proposed arrangement of Mobile Laboratory and DSRP skid for PSDF field test.
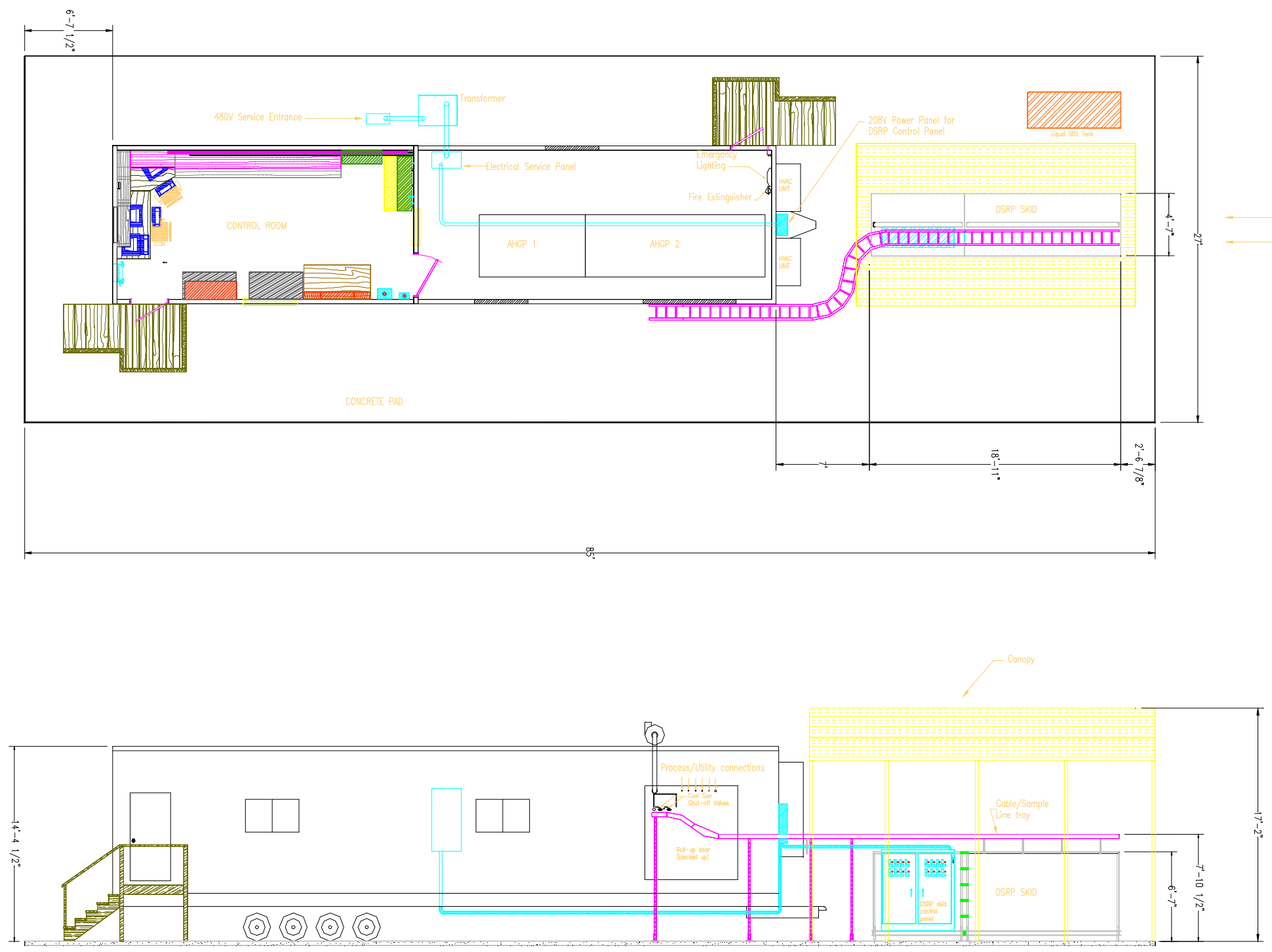
Figure 4. Revised proposed arrangement of Mobile Laboratory and DSRP skid for PSDF field test.
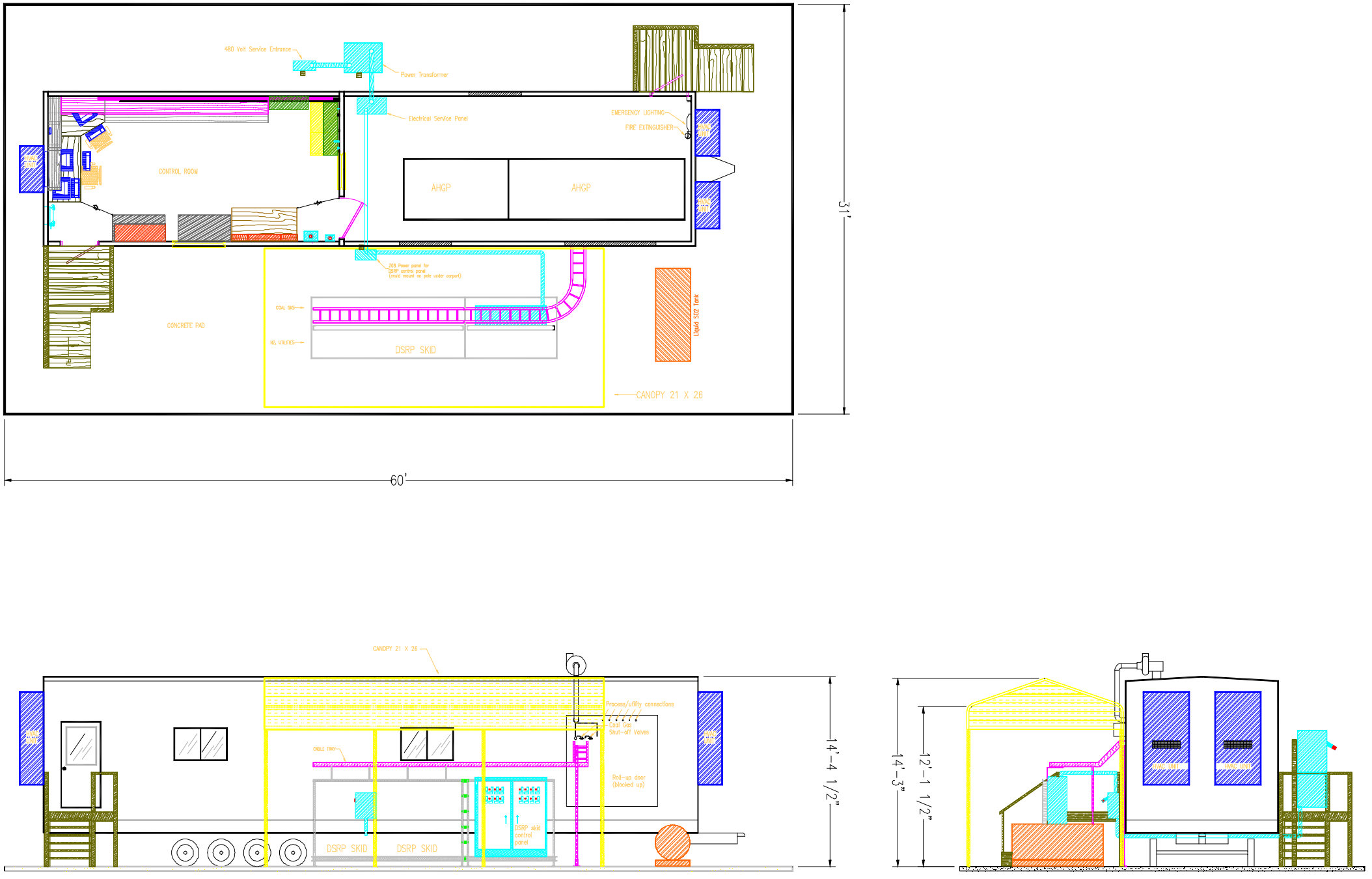